\title{
A Path Analysis to Investigate the Interaction between Serum, Urinary and Demographic Factors Influencing Urine Calcium in Kidney Stone Formers
}

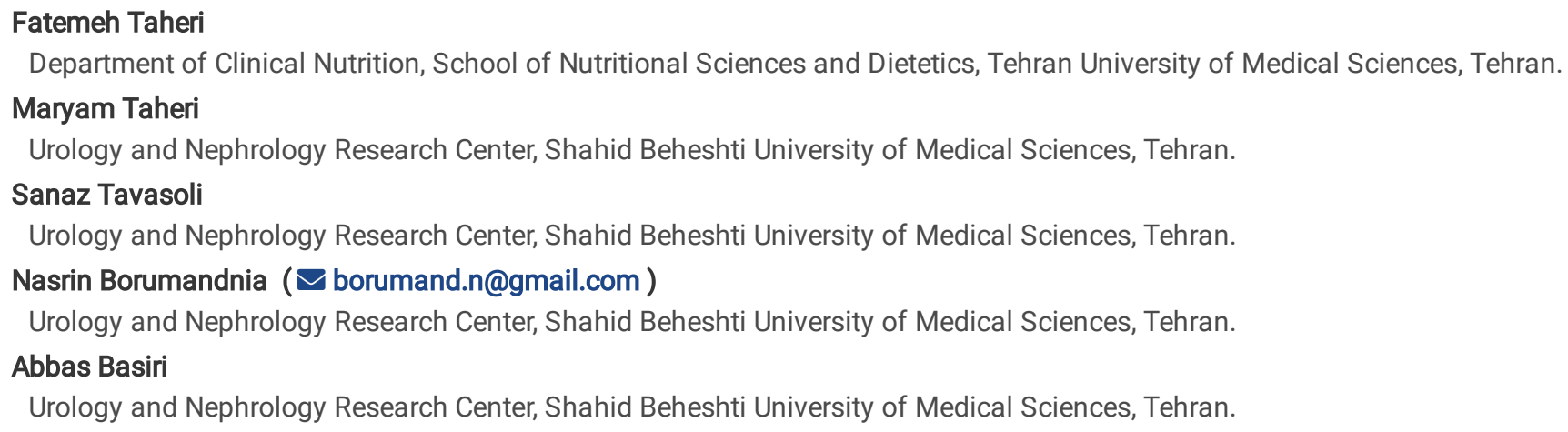




\section{Abstract}

Background: Hypercalciuria is one of the most important urinary risk factors in kidney stone formers. This study aimed to delineate the interaction of some demographic, serum, and urinary risk factors influencing 24-hour urinary (24-U) calcium excretion.

Methods: This study was secondary data analysis, using data from 593 kidney stone patients referred to the Labbafinejad kidney stone prevention clinic from March 2015 to May 2019. The study considered serum, urinary and demographic factors that interact to influence 24-U calcium using path analysis.

Results: The results showed that age and weight had an indirect effect on $24-\mathrm{U}$ calcium. Among serum variables, PTH and creatinine had a significant direct effect on 24-U calcium. In comparison, 25-hydroxy vitamin D (25(OH)D) and phosphorus appeared to influence 24-U calcium through serum parathormone. Regarding 24-U metabolites, 24-U sodium, 24-U Urea, and 24-U citrate had a significant direct effect on 24-U calcium. Moreover, 24-U creatinine has a significant direct and indirect effect on 24-U calcium through 24-U citrate and 24-U Urea as mediating variables. 24-U citrate had the most effect on 24-U calcium, following 24-U creatinine, 24-U Urea, 24-U sodium, serum creatinine, and weight.

Conclusion: Except for serum calcium, all other predictors had direct and/or indirect effects on 24-U calcium. Serum 25(OH)D had a negligible indirect effect on 24-U calcium. Controlling dietary intake of protein and sodium and bodyweight seems very important in kidney stone formers with hypercalciuria.

\section{Background}

In recent decades, the incidence and prevalence of kidney stones have increased worldwide. Urolithiasis is a common cause of morbidity with a lifetime risk of $5-12 \%$ in Europe and the USA $(1,2)$. Since kidney stones are a potential risk factor for irreversible renal function loss with a high disease burden, many studies have been conducted to explore kidney stone formation's pathophysiology (3).

The most common component of nearly $80 \%$ of kidney stones is made of calcium in the form of calcium oxalate and, to a lesser extent, calcium phosphate (4). Therefore, controlling excess calcium excretion in the urine (hypercalciuria) is very important for kidney stone prevention (4). Hypercalciuria is one of the most common urine metabolic abnormalities among calcium stone formers, with a prevalence of $35-65 \%$. Excess calcium excretion in the urine could be responsible for the supersaturated status of urinary calcium salts and lead to crystallization (5).

Urine calcium excretion is affected directly or indirectly by various factors (such as demographic or metabolic) that are not entirely known. Calcium homeostasis in the body is mainly regulated via complex interactions between various organs, including the intestines, kidney, and bones (6). According to the regulatory mechanisms, hypercalciuria is classified as intestinal absorptive, renal leak, or parathyroid resorptive hypercalciuria (7). Hypercalciuria with no identifiable metabolic cause was defined as idiopathic, which is the cause for at least $50 \%$ of the calcium stones (6).

Two important hormones, which play a crucial role in calcium homeostasis, are parathyroid hormone (PTH) and vitamin D. Active form of vitamin D or calcitriol stimulates intestinal calcium absorption and bone resorption and decreases renal calcium excretion. PTH is secreted in response to extracellular calcium level alterations and provides minute-by-minute regulation of serum calcium through stimulation of renal reabsorption, bone resorption, and on a more chronic basis, stimulation of intestinal absorption by promoting the conversion of 25-hydroxy vitamin D (25(OH)D) to calcitriol $(8,9)$. Thus, inadequate or excessive levels of PTH or calcitriol could dysregulate these mechanisms and cause hypercalciuria.

In addition to the PTH and calcitriol, urinary parameters such as urinary sodium, citrate, and demographic factors can affect urinary calcium levels $(10-12)$. An in-depth understanding of this complex interaction between different variables that regulate calcium homeostasis could help to understand the pathophysiology of idiopathic hypercalciuria and improve its management. However, population-based data on this area is scarce, and the complex direct and indirect effects of serum and urinary metabolites on urine calcium have surprisingly not been fully explored. Thus, this study aims are to assess the interrelationship between serum, urinary and demographic factors that may affect urine calcium in a population of calcium stone formers. Using pathway analysis, we hypothesize and test how urine metabolites and serum variables may, directly and indirectly, influence urine calcium.

\section{Method}

This study was a secondary data analysis using the baseline data of our previous study (13). This retrospective study included data from kidney stone patients referred to the Labbafinejad kidney stone prevention clinic from March 2015 to May 2019. Patients who were $\geq 18$ years old and had undergone serum assessment for 25(OH)D were included in the previous study. The current study considered serum, urinary, and 
demographic factors of those patients to evaluate their effect on 24-hour urine calcium (24-U Ca) using path analysis. Patients who had a known history of primary hyperparathyroidism or any chronic diseases that could affect urine calcium (such as sarcoidosis), had a history of chronic kidney disease, consuming any medication interfering with calcium hemostasis three months before the assessment (such as thiazides, steroids, or calcium supplements), were pregnant or lactating, or had urinary tract infection at the time of assessment were excluded. Details regarding participant recruitment were presented elsewhere (13). In addition to age and weight, the twenty-four-hour urine metabolites in terms of creatinine, urea, citrate, sodium, as well as serum variables including phosphorus $(\mathrm{P}), \mathrm{PTH}, \mathrm{calcium}(\mathrm{Ca}), 25(\mathrm{OH}) \mathrm{D}$, and creatinine (Cr) were considered to investigate their effect on 24-U Ca.

Path Analysis, an extension of the regression model, is a statistical technique used to examine causal relationships between two or more variables, and its pathways represent the hypotheses of researchers. This analysis provides a comprehensive picture of the associations between the predictors and dependent variable. Here, path analysis was used to determine the pathways by which urine metabolites and serum variables interact to influence the primary outcome variable, 24-U Ca. The path model, presented in figure 1, was developed by review the articles (12), textbooks (4) and the consensus of experts who specialize in various aspects of kidney stone prevention (14).

In this model, the direct effect represents the direct impact of one predictor on the outcome while not transmitted through a third variable. The indirect effect is the impact of a predictor on the outcome transmitted by a third variable. The total effect of a predictor on the response is obtained by summing direct and indirect effects related to different pathways. The size of the effects is reported both in standardized and unstandardized terms. Unstandardized coefficients used the original variables' measurement scale and indicated the strength of the relationship between variables. Standardized coefficients were values transformed into the same unit and used to compare the effects of variables on the response. The study was carried out in accordance with the guidelines of the Helsinki Declaration (Fortaleza, Brazil, October 2013).

\section{Statistical methods}

Descriptive statistics including frequency and percentage for qualitative variables and means with standard deviations for quantitative ones were used. The mean of quantitative variables between patients with 24-U Ca less than 200 mg and 24-U Ca more than 200 mg was compared using independent samples t-test. Pearson correlation was calculated to determine the relationship between urine metabolites and serum variables. The main analytic plan, path analysis, involved the primary outcome variable, $24-\mathrm{U} \mathrm{Ca}$, and the predictor variables of interest, including age, weight, 24-urine metabolites and serum variable. The adequacy of the path model was tested using the Relative Chi-Square (CMIN/DF), and the Root Mean Squared Error of Approximation (RMSEA). The RMSEA<0.1, and CMIN/DF of 1-5, indicate an acceptable fit to the data. Path analyses were conducted using the Amos 24.0.0, an IBM SPSS Statistics module. Other statistical analyses were carried out with SPSS 25.0. The significance level was set at 0.05 .

\section{Results}

Of the 1021 evaluated individuals, 593 (58\%) had complete data and were included in the analyses. Table 1 summarizes the characteristics of the study participants, and compares patients with 24-U Ca less than $200 \mathrm{mg} /$ day and 24-U Ca more than $200 \mathrm{mg} / \mathrm{day}$. 
Table 1

Descriptive characteristics of study participants according to 24-U Ca.

\begin{tabular}{|c|c|c|c|c|}
\hline Variables & $\begin{array}{l}24-U \mathrm{Ca} \\
>200 \mathrm{mg}\end{array}$ & $\begin{array}{l}24-\mathrm{U} \mathrm{Ca} \\
<=200 \mathrm{mg}\end{array}$ & Total & p-value ${ }^{a}$ \\
\hline Age & $46(11)$ & $49(13)$ & $48(12)$ & $0.001^{\star \star}$ \\
\hline Weight & $81.92(14.2)$ & $79.3(14.0)$ & $80.3(14.1)$ & $0.028^{\star}$ \\
\hline Serum phosphorus & $3.471(0.62)$ & $3.52(0.67)$ & $3.50(0.65)$ & 0.319 \\
\hline Serum parathormone & $47.89(26.32)$ & $56.01(30.12)$ & $53.00(29.02)$ & $0.001^{\star \star}$ \\
\hline Serum calcium & $9.51(0.51)$ & $9.58(0.53)$ & $9.55(0.52)$ & 0.120 \\
\hline Serum 25-hydroxy vitamin D & $24.43(17.81)$ & $23.90(17.40)$ & $24.10(17.54)$ & 0.721 \\
\hline Serum creatinine & $1.09(0.19)$ & $1.20(0.38)$ & $1.16(0.33)$ & $<0.001^{\star \star \star}$ \\
\hline 24-hour urine urea & $28.26(11.17)$ & $23.62(9.32)$ & $25.36(10.29)$ & $<0.001^{\star \star \star}$ \\
\hline 24-hour urine sodium & $172.31(61.80)$ & $146.84(56.32)$ & 156.38 (59.67) & $<0.001^{\star \star \star}$ \\
\hline 24-hour urine citrate & 636.09 (334.61) & 476.89 (261.20) & 536.49 (300.64) & $<0.001^{\star \star \star}$ \\
\hline \multicolumn{5}{|c|}{ All values stand for Mean (Standard deviation). 24-U Ca: 24-hour urine calcium. } \\
\hline \multicolumn{5}{|l|}{ a Independent sample t-test } \\
\hline
\end{tabular}

As results showed, the mean of age, weight, serum PTH, serum Cr, 24-U Urea, 24-U Na, and 24-U Cit were significantly different between groups ( $p$-value $<0.05$ for all analyses). Besides, bivariate analysis was used to assess the existing correlations between variables. Table 2 presents Pearson's correlation coefficients. The 24-U Ca had a significant positive correlation with weight, 24-U Urea, 24-U Cr, 24-U Na, and 24-U Cit, and had a significant negative correlation with age and serum $\mathrm{Cr}$. 
Table 2

Sample correlation matrix among influencing variables and 24-U calcium.

\begin{tabular}{|c|c|c|c|c|c|c|c|c|c|c|c|}
\hline & Age & Weight & $\begin{array}{l}\text { S } \\
\text { phosphorus }\end{array}$ & $\begin{array}{l}\text { S } \\
\text { PTH }\end{array}$ & $\begin{array}{l}\text { S } \\
\text { calcium }\end{array}$ & $\begin{array}{l}S \\
25(O H) D\end{array}$ & $\begin{array}{l}\text { S } \\
\text { creatinine }\end{array}$ & $\begin{array}{l}24-U \\
\text { urea }\end{array}$ & $\begin{array}{l}24-U \\
\text { creatinine }\end{array}$ & $\begin{array}{l}24-U \\
\text { sodium }\end{array}$ & $\begin{array}{l}24-U \\
\text { citrate }\end{array}$ \\
\hline $\begin{array}{l}24-U \\
\text { calcium }\end{array}$ & $-.121^{\star \star}$ & $.105^{*}$ & -.036 & -.032 & .065 & .052 & $-.154^{\star *}$ & $.169^{\star *}$ & $.264^{\star \star}$ & $.297^{\star *}$ & $.299^{\star *}$ \\
\hline 24-U citrate & -.010 & .076 & -.024 & -.025 & -.065 & .051 & $-.207^{\star \star}$ & .048 & $.146^{\star \star}$ & $.210^{\star *}$ & 1 \\
\hline $\begin{array}{l}24-U \\
\text { sodium }\end{array}$ & -.044 & $.225^{* *}$ & -.021 & -.025 & .014 & .007 & -.052 & $.101^{*}$ & $.397^{\star *}$ & 1 & \\
\hline $\begin{array}{l}24-U \\
\text { creatinine }\end{array}$ & $-.157^{\star \star}$ & $.436^{* *}$ & $-.087^{*}$ & -.051 & .061 & $-.111^{\star *}$ & $.121^{\star *}$ & $.130^{\star *}$ & 1 & & \\
\hline 24-U urea & .050 & .006 & -.029 & $.154^{\star \star}$ & .007 & .043 & -.013 & 1 & & & \\
\hline $\begin{array}{l}\text { S } \\
\text { Creatinine }\end{array}$ & $.192^{* \star}$ & .018 & .016 & .045 & .031 & .025 & 1 & & & & \\
\hline S 25(OH)D & $.171^{\star *}$ & $-.133^{*}$ & .042 & $-.106^{*}$ & .016 & 1 & & & & & \\
\hline S calcium & -.041 & $-.087^{*}$ & .050 & $.125^{*}$ & 1 & & & & & & \\
\hline S PTH & .068 & -.030 & $-.192^{\star \star}$ & 1 & & & & & & & \\
\hline $\begin{array}{l}\text { S } \\
\text { phosphorus }\end{array}$ & .019 & .032 & 1 & & & & & & & & \\
\hline Weight & .027 & 1 & & & & & & & & & \\
\hline \multicolumn{12}{|c|}{ S: serum. 24-U: 24-hour urine. PTH: parathormone. 25(OH)D: 25-hydroxy vitamin D } \\
\hline
\end{tabular}

\section{Path analysis result}

The path analysis model is depicted in Fig. 1, which presents hypotheses about the relationships between variables. This model had a good fit with a CMIN/DF $=187.807 / 44=4.26$, RMSEA $=0.086(\mathrm{Cl}: 0.076,0.097)$. The parameter estimates derived from the path analysis model are reported in Table 3. Furthermore, the total, direct and indirect effects of variables on the main outcome (24-U Ca) are provided in Table 4. 
Table 3

Parameter estimates derived from the path analysis for Model

\begin{tabular}{|c|c|c|c|c|c|}
\hline Outcome variables & & Predictor variables & Estimate & S.E. & p-value \\
\hline S 25(OH)D & $<-$ & Age & 0.182 & 0.059 & $0.002^{\star \star}$ \\
\hline S PTH & $<-$ & S phosphorus & -7.506 & 1.825 & $<0.001^{\star \star \star}$ \\
\hline $24-U$ creatinine & $<-$ & Weight & 0.010 & 0.001 & $<0.001^{\star \star \star}$ \\
\hline S PTH & $<-$ & S 25(OH)D & -0.108 & 0.068 & 0.110 \\
\hline $24-U$ creatinine & $<-$ & Age & -0.004 & 0.001 & $<0.001^{\star \star \star}$ \\
\hline 24-U sodium & $<-$ & Weight & 0.939 & 0.170 & $<0.001^{\star \star \star}$ \\
\hline S calcium & $<-$ & S PTH & 0.000 & 0.001 & 0.784 \\
\hline S creatinine & $<-$ & Age & 0.006 & 0.001 & $<0.001^{\star \star \star}$ \\
\hline 24-U citrate & $<-$ & 24-U creatinine & 91.249 & 36.535 & $0.013^{\star}$ \\
\hline 24-U urea & $<-$ & Weight & -0.007 & 0.030 & 0.816 \\
\hline 24-U urea & $<-$ & 24-U creatinine & 13.352 & 1.247 & $<0.001^{\star \star \star}$ \\
\hline 24-U calcium & $<-$ & 24-U citrate & 0.066 & 0.011 & $<0.001^{\star \star \star}$ \\
\hline 24-U calcium & $<-$ & S creatinine & -34.065 & 9.578 & $<0.001^{\star \star \star}$ \\
\hline 24-U calcium & $<-$ & S calcium & -.669 & 6.076 & 0.912 \\
\hline 24-U calcium & $<-$ & $24-U$ sodium & 0.220 & 0.054 & $<0.001^{\star \star \star}$ \\
\hline 24-U calcium & $<-$ & 24-U urea & 1.817 & 0.343 & $<0.001^{\star \star \star}$ \\
\hline 24-U calcium & $<-$ & 24-U creatinine & 27.616 & 10.575 & $0.009^{\star \star}$ \\
\hline 24-U calcium & $<-$ & S 25(OH)D & 0.019 & 0.182 & 0.915 \\
\hline 24-U calcium & $<-$ & S PTH & -0.254 & 0.111 & $0.023^{*}$ \\
\hline \multicolumn{6}{|c|}{ S.E.: standard error. S: serum. 24-U: 24-hour urine. 25(OH)D: 25-hydroxy vitamin D. PTH: parathormone } \\
\hline \multicolumn{6}{|c|}{${ }^{\star} p<0.05 .{ }^{* *} p<0.01 .{ }^{* \star *} p<0.001$} \\
\hline
\end{tabular}


Table 4

Direct, indirect, and total effects of all predictor variables on 24-U calcium derived from the path analysis, in terms of unstandardized and standardized coefficients.

\begin{tabular}{|c|c|c|c|c|c|c|}
\hline \multirow[t]{2}{*}{ Predictor variables } & \multicolumn{3}{|c|}{ Unstandardized coefficient } & \multicolumn{3}{|c|}{ Standardized coefficient } \\
\hline & Direct effect & Indirect effect & Total effect & Direct effect & Indirect effect & Total effect \\
\hline Age & - & -0.394 & -0.394 & - & -0.056 & -0.056 \\
\hline Weight & - & 0.780 & 0.780 & - & 0.128 & 0.128 \\
\hline S creatinine & -34.065 & - & -34.065 & -0.131 & - & -0.131 \\
\hline S calcium & -0.669 & - & -0.669 & -0.004 & - & -0.004 \\
\hline $\mathrm{S} 25(\mathrm{OH}) \mathrm{D}$ & 0.019 & 0.028 & 0.047 & 0.004 & 0.006 & 0.010 \\
\hline S PTH & -0.254 & - & -0.254 & -0.086 & - & -0.086 \\
\hline S phosphorus & - & 1.907 & 1.907 & - & 0.014 & 0.014 \\
\hline 24-U citrate & 0.066 & - & 0.066 & 0.229 & - & 0.229 \\
\hline 24-U sodium & 0.220 & - & 0.220 & 0.152 & - & 0.152 \\
\hline 24-U urea & 1.817 & - & 1.817 & 0.217 & - & 0.217 \\
\hline 24-U creatinine & 27.616 & 30.256 & 57.872 & 0.108 & 0.118 & 0.226 \\
\hline
\end{tabular}

The results showed that age and weight had an indirect effect on $24-U \mathrm{Ca}(\beta=-0.394$ and $\beta=0.780$, respectively, $P<0.05)$. The negative coefficient suggested that 24-U Ca is lowered with an increase in age. Furthermore, the increasing weight will indirectly increase 24-U Ca. Regarding serum variables, $25(\mathrm{OH}) \mathrm{D}$ did not significantly affect 24-U Ca. However, it had an indirect effect on 24-U Ca with serum PTH participation $(\beta=0.028, P<0.05)$. Conversely, serum PTH directly affected $24-U \mathrm{Ca}(\beta=-0.254, P=0.023)$ without an indirect effect. Serum Ca did not have any direct or indirect effect; however, Serum $P$ appeared to influence $24-U$ Ca indirectly $(\beta=1.907, P<0.05)$. Serum Cr had a significant direct effect on $24-\mathrm{U} \mathrm{Ca}(\beta=-34.065, \mathrm{P}<0.001)$.

Regarding 24-hour urine metabolites, it was shown that 24-U Na, 24-U Urea, and 24-U Cit had a significant direct effect on 24-U Ca ( $\beta=0.220, \beta$ $=1.817, \beta=0.066$, respectively, $\mathrm{P}<0.001) .24-\mathrm{U} \mathrm{Cr}$ has a significant direct and indirect effect on 24-U Ca with participation of 24-U Cit and 24-U Urea as mediating variables $(\beta=27.616$ for direct effect and $\beta=30.256$ for indirect effect, $P<0.05)$.

According to standardized coefficients Table 4, 24-U Cit had the most effect on 24-U Ca, following 24-U Cr, 24-U Urea, 24-U Na, serum Cr, and weight. Serum Ca had the lowest effect on 24-U Ca.

\section{Discussion}

According to the studies, several risk factors could contribute to calcium kidney stones. Among them, hypercalciuria is one of the most common urine metabolic abnormalities (5). The excretion of calcium in the urine might be affected by serum variables, demographics, and other urinary metabolites. Our study revealed that 24-U Ca excretion decreases with increasing age, serum PTH and serum Cr. Conversely, 24-U Ca increases with weight gain, increasing 24-U Na, 24-U Cit, 24-U Urea, and 24-U Cr.

Among demographic factors, we included age and weight in our analysis. Previously, two large-sample studies found no association between age and hypercalciuria $(10,11)$. However, Taylor et al. reported an inverse association between age and 24-U Ca; every five-year increase in age was associated with a $6 \mathrm{mg}(95 \% \mathrm{Cl} 4$ to $9 \mathrm{mg} / \mathrm{d})$ decrease in 24-U Ca (12). Our analyses showed that age indirectly affected urine calcium through serum 25(OH)D, serum $\mathrm{Cr}$ and 24-U Cr.

Previous studies showed that higher weight is associated with higher urinary calcium excretion (15). Our findings showed that body weight indirectly affects 24-U Ca through 24-U Na, 24-U Urea, and 24-U Cr. These results suggest that the effect of weight on urinary calcium excretion may be in part due to higher protein and salt intake in patients with higher weight. More studies regarding this finding are warranted.

Vitamin D causes a positive balance of calcium in the body through stimulation of intestinal calcium absorption. However, since different studies' results are inconsistent $(11,16-21)$, the relationship between serum vitamin $\mathrm{D}$ and $24-\mathrm{U}$ calcium excretion is under debate. A recent meta-analysis, including twenty-two observational studies (3510 kidney stone formers and 19,718 controls), revealed that 25(OH)D was similar in both groups. Conversely, 1,25-dihydroxy vitamin D (1,25(OH)2D) was significantly higher in stone formers than controls. More 
detailed studies on kidney stone formers indicated that hypercalciuric patients had significantly higher 1,25(OH)2D and 25(OH)D compared with normocalciuric stone patients and non-stone forming controls (22). Two population-based studies, InChianti Study (23) and Swiss Survey on Salt Intake Study (10), showed that the level of serum $25(\mathrm{OH}) \mathrm{D}$ was positively associated with urinary calcium excretion in men but not in women. Other studies failed to observe any correlations between 25(OH)D and urinary calcium excretion (19-21). The results of our previous study (24) showed that the 24-U Ca increased in vitamin D supplemented patients, which was not associated with serum 25(OH)D or PTH changes. Other results of that study suggested that the increase in 24-U Ca might be due to other factors such as dietary sodium and protein intake. In line with our previous findings, the current study results showed that serum 25(OH)D did not have a direct effect on $24-\mathrm{U}$ Ca, and the indirect effect was through serum PTH. This effect is negligible; therefore, the treatment of hypovitaminosis D could be safe in kidney stone formers, in case other variables, such as sodium intake, are controlled. Further randomized clinical trials are needed in this regard.

PTH is responsible for minute-by-minute regulation of serum ionized calcium, through stimulation of renal calcium reabsorption and bone resorption. Furthermore, PTH stimulates the conversion of $25(\mathrm{OH}) \mathrm{D}$ to its active hormonal form $(1,25(\mathrm{OH}) 2 \mathrm{D})$ in the kidney, thereby promoting absorption of calcium in the small intestine $(8,9)$. A negative correlation between serum PTH and urinary calcium excretion is shown in previous studies, which is considered as the normal process of serum calcium balance. Similarly, our current results showed that PTH had a significant inverse effect on 24-U Ca directly. However, excessive PTH secretion from a parathyroid adenoma (primary hyperparathyroidism) leads to excessive bone resorption and increased renal synthesis of 1,25(OH)2D, which in turn enhances intestinal absorption of calcium. Therefore, the net effect is elevated serum calcium levels, which leads to higher urine calcium. Conversely, the level of urine calcium is decreased in secondary hyperparathyroidism, due to increased calcium resorption from kidney tubules. One of the common causes of secondary hyperparathyroidism are vitamin D deficiency, therefore the level of serum PTH is decreased after vitamin D supplementation.

The previous observational findings of the association between serum Ca and excretion of Ca in 24-h urine are inconsistent. The study, which was conducted on 1293 participants (624 men and 669 women), found a positive association between serum Ca and 24-U Ca in women but not men (10), while the InChianti study (595 subjects including 302 men and 293 women) observed this association in men but not women (23). In an interventional small-sized study by Peacock et al. (25) on 72 individuals, a positive association was observed between serum and urinary $\mathrm{Ca}$ in both men and women. Our results revealed that there is no significant direct or indirect association between serum Ca and $24-\mathrm{U}$ Ca. Normally, serum calcium is tightly controlled in a narrow range during calcium hemostasis. Since we excluded patients with primary hyperparathyroidism or any other diseases affecting serum $\mathrm{Ca}$, total serum Ca was in a narrow range in all patients, and we could not find any association between serum and urine Ca. However, serum P appears to influence 24-U Ca indirectly. It seems that the effect of serum P on urinary Ca levels may be more prominent, and further studies are needed in this field.

In line with previous studies $(11,12)$, our results indicated that higher excretion of Na was positively correlated with $24-\mathrm{U}$ Ca. The positive effect of $\mathrm{Na}$ intake, measured through 24-U Na, on urinary Ca excretion has been demonstrated in previous studies (26, 27). Because sodium and $\mathrm{Ca}$ are reabsorbed at common sites in the renal tubules, the direct correlation of sodium and Ca in the urine is expected (28).

The relationship between urinary citrate and Ca may be challenging to discuss. Taylor et al. (12) discussed that since acid load could increase urinary $\mathrm{Ca}$ and decrease urinary citrate, it would be reasonable to expect an inverse association between urinary citrate and Ca. Moreover, some studies reported that potassium citrate consumption could reduce urinary $\mathrm{Ca}(29,30)$. However, we observed a marked direct effect of 24-U Cit on urinary Ca excretion, which was reported by other studies too $(11,12)$. Other factors such as dietary Ca intake may play a part in such association. Further studies are needed to elucidate the topic.

Data about the relationship between 24-U Ca and other factors included in our analysis are limited. Taylor et al. did not find any associations between urinary $\mathrm{Cr}$ and $\mathrm{Ca}$ after multivariate adjustment. However, we observed a positive effect of both serum and urinary $\mathrm{Cr}$ on $24-\mathrm{U} \mathrm{Ca}$. Besides, our study revealed a direct effect of 24-U Urea on 24-U Ca. Since 24-U Urea is a substitute for dietary protein intake, our results suggested an increase in 24-U Ca with high protein intake. This finding is in line with existing studies. However, since we did not evaluate the 24-U sulfate or dietary intake, we could not evaluate the effect of animal and vegetable protein intake on 24-U Ca separately.

This study has some limitations. First, we could not assess the effect of calcium on PTH since we did not test ionized calcium. Second, the dietary intake was not available in our study. Third, additional factors affecting 24-U Ca may not be considered in our model.

\section{Conclusion}

In conclusion, urinary calcium excretion is higher in younger obese patients with normal kidney function. Except for serum calcium, all other predictors had direct and/or indirect effect on 24-U calcium. Serum 25(OH)D had a negligible indirect effect on 24-U calcium. Controlling dietary intake of protein and sodium and body weight seems very important in kidney stone formers with hypercalciuria.

\section{Declarations}




\section{Ethics approval and consent to participate}

The Ethics Committee of the Urology and Nephrology Research Center at Shahid Beheshti University of Medical Sciences approved the study (ethic code, IR. SBMU.UNRC.1395.15).

\section{Consent for publication}

Not Applicable.

\section{Availability of data and material}

Data and materials can be made available upon request.

\section{Competing interests}

The authors declare that they have no competing interests.

\section{Funding}

No specific funding for this work.

\section{Authors' contributions}

Conceptualization, N.B., S.T., M.T., F.T.; Acquisition of Data: S.T., and M.T.; Methodology, analysis, N.B.; Writing-original draft preparation, F.T, and N.B.; Writing-review and editing, F.T., S.T., M.T., N.B.; Administrative and Supervision, A.B.;

\section{Acknowledgements}

Not Applicable.

\section{References}

1. Bartoletti R, Cai T, Mondaini N, Melone F, Travaglini F, Carini M, et al. Epidemiology and risk factors in urolithiasis. Urologia internationalis. 2007;79(Suppl. 1):3-7.

2. Stamatelou KK, Francis ME, Jones CA, Nyberg Jr LM, Curhan GC. Time trends in reported prevalence of kidney stones in the United States: 1976-1994. Kidney international. 2003;63(5):1817-23.

3. Rule AD, Krambeck AE, Lieske JC. Chronic kidney disease in kidney stone formers. Clinical Journal of the American Society of Nephrology. 2011;6(8):2069-75.

4. Partin AW, Wein AJ, Kavoussi LR, Peters CA, Dmochowski RR. Campbell Walsh Wein Urology, E-Book: Elsevier Health Sciences; 2020.

5. Coe FL, Parks JH, Asplin JR. The pathogenesis and treatment of kidney stones. New England Journal of Medicine. 1992;327(16):114152.

6. Levy FL, Adams-Huet B, Pak CY. Ambulatory evaluation of nephrolithiasis: an update of a 1980 protocol. The American journal of medicine. 1995;98(1):50-9.

7. Pak CY, Ohata M, Lawrence EC, Snyder W. The Hypercalciurias causes, parathyroid functions, and diagnostic criteria. The Journal of clinical investigation. 1974;54(2):387-400.

8. Potts JT. Parathyroid hormone: past and present. Journal of Endocrinology. 2005;187(3):311-25.

9. Holick MF. Vitamin D deficiency. New England Journal of Medicine. 2007;357(3):266-81.

10. Rathod A, Bonny O, Guessous I, Suter PM, Conen D, Erne P, et al. Association of urinary calcium excretion with serum calcium and vitamin D levels. Clinical Journal of the American Society of Nephrology. 2015;10(3):452-62.

11. Kim WT, Kim Y-J, Yun SJ, Shin K-S, Choi YD, Lee SC, et al. Role of 1, 25-dihydroxy vitamin D3 and parathyroid hormone in urinary calcium excretion in calcium stone formers. Yonsei medical journal. 2014;55(5):1326. 
12. Taylor EN, Curhan GC. Demographic, dietary, and urinary factors and 24-h urinary calcium excretion. Clinical Journal of the American Society of Nephrology. 2009;4(12):1980-7.

13. Tavasoli S, Taheri F, Bagheri Amiri F, Borumandnia N, Basiri A, Parvin M, et al. The prevalence of vitamin D deficiency, its proposing factors and association with 24-hour urine metabolites among Iranian kidney stone formers. Iran J Kidney Dis. 2021;In press.

14. Williams JC, Gambaro G, Rodgers A, Asplin J, Bonny O, Costa-Bauzá A, et al. Urine and stone analysis for the investigation of the renal stone former: a consensus conference. Urolithiasis. 2020:1-16.

15. Powell CR, Stoller ML, Schwartz BF, Kane C, Gentle DL, Bruce JE, et al. Impact of body weight on urinary electrolytes in urinary stone formers. Urology. 2000;55(6):825-30.

16. Berlin T, Björkhem I, Collste L, Holmberg I, Wijkström H. Relation between hypercalciuria and vitamin D3-status in patients with urolithiasis. Scandinavian journal of urology and nephrology. 1982;16(3):269-73.

17. Giannini S, Nobile M, Castrignano R, Pati T, Tasca A, Villi G, et al. Possible link between vitamin D and hyperoxaluria in patients with renal stone disease. Clinical Science. 1993;84(1):51-4.

18. Jarrar K, Amasheh R, Graef V, Weidner W. Relationship between 1, 25-dihydroxyvitamin-D, calcium and uric acid in urinary stone formers. Urologia internationalis. 1996;56(1):16-20.

19. Netelenbos JC, Jongen MJ, van der Vijgh WJ, Lips P, van Ginkel FC. Vitamin D status in urinary calcium stone formation. Archives of internal medicine. 1985;145(4):681-4.

20. Eisner BH, Thavaseelan S, Sheth S, Haleblian G, Pareek G. Relationship between serum vitamin D and 24-hour urine calcium in patients with nephrolithiasis. Urology. 2012;80(5):1007-10.

21. Tang J, McFann KK, Chonchol MB. Association between serum 25-hydroxyvitamin D and nephrolithiasis: the National Health and Nutrition Examination Survey III, 1988-94. Nephrology Dialysis Transplantation. 2012;27(12):4385-9.

22. Hu H, Zhang J, Lu Y, Zhang Z, Qin B, Gao H, et al. Association between circulating vitamin D level and urolithiasis: a systematic review and meta-analysis. Nutrients. 2017;9(3):301.

23. Vezzoli G, Soldati L, Arcidiacono T, Terranegra A, Biasion R, Russo CR, et al. Urinary calcium is a determinant of bone mineral density in elderly men participating in the InCHIANTI study. Kidney international. 2005;67(5):2006-14.

24. Taheri M, Tavasoli S, Shokrzadeh F, Amiri FB, Basiri A. Effect of vitamin D supplementation on 24-hour urine calcium in patients with calcium Urolithiasis and vitamin D deficiency. International braz j urol. 2019;45(2):340-6.

25. Peacock M, Robertson W, Nordin B. Relation between serum and urinary calcium with particular reference to parathyroid activity. The Lancet. 1969;293(7591):384-6.

26. Muldowney FP, Freaney R, Moloney MF. Importance of dietary sodium in the hypercalciuria syndrome. Kidney international. 1982;22(3):292-6.

27. Sakhaee K, Harvey JA, Padalino PK, Whitson P, Pak CY. The potential role of salt abuse on the risk for kidney stone formation. The Journal of urology. 1993;150(2 Part 1):310-2.

28. Mahan L, Food RJKs. the Nutrition Care Process. Saunders Philadelphia: Saunders; 2016.

29. Song Y, Hernandez N, Shoag J, Goldfarb DS, Eisner BH. Potassium citrate decreases urine calcium excretion in patients with hypocitraturic calcium oxalate nephrolithiasis. Urolithiasis. 2016;44(2):145-8.

30. Moseley KF, Weaver CM, Appel L, Sebastian A, Sellmeyer DE. Potassium citrate supplementation results in sustained improvement in calcium balance in older men and women. Journal of bone and mineral research: the official journal of the American Society for Bone and Mineral Research. 2013;28(3):497-504.

\section{Figures}




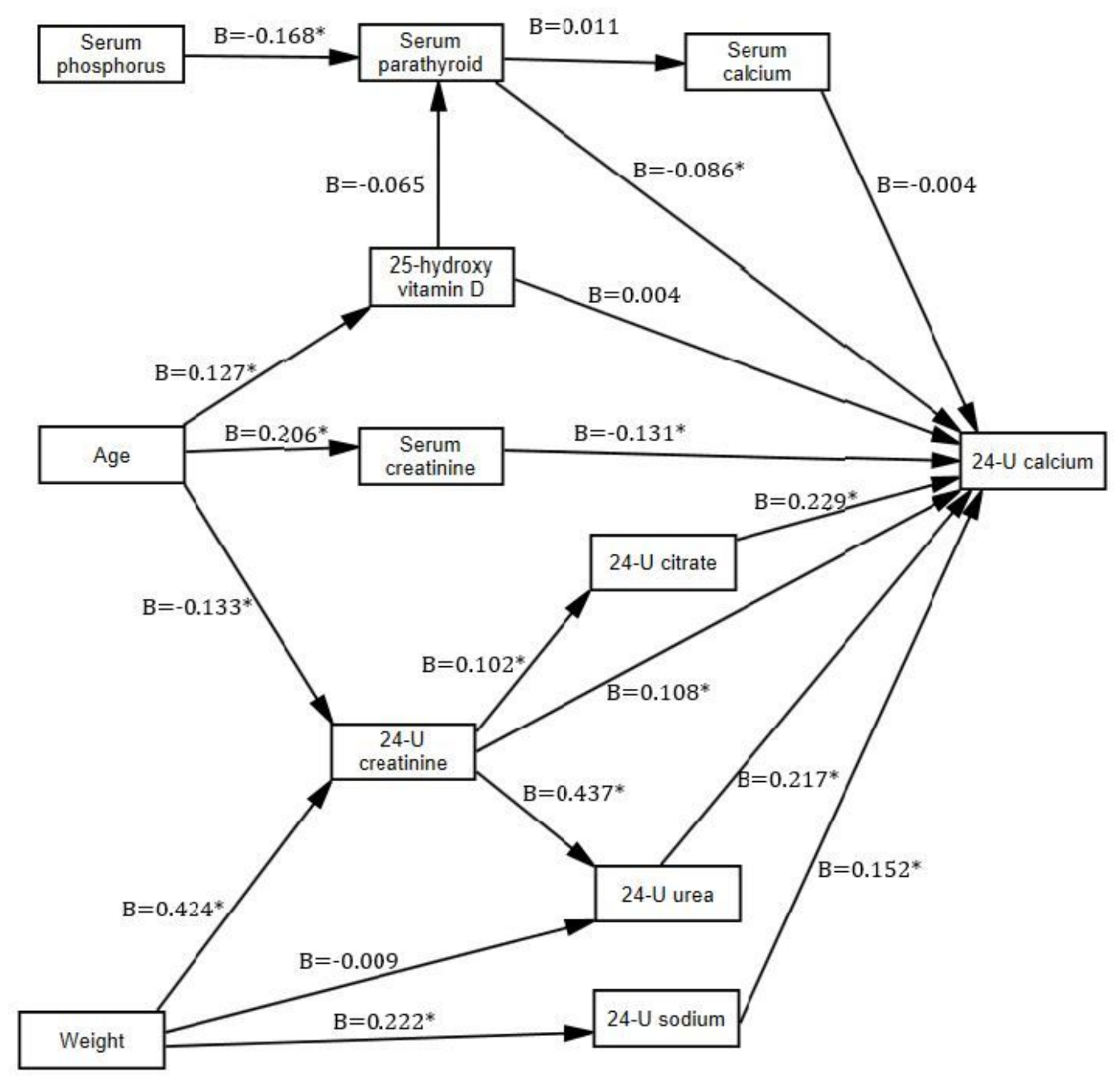

\section{Figure 1}

Illustration of the potential pathways linking urine and serum metabolites, which interact to influence 24-hour urine calcium; Results of path analysis in terms of standardized coefficients are presented. 24-U: 24-hour urine. ${ }^{*} p<0.05$. 